\title{
INSIGHTS FROM THE IMPLEMENTATION OF A FLIPPED CLASSROOM APPROACH WITH THE USE OF A COMMERCIAL LEARNING MANAGEMENT SYSTEM
}

\author{
OnUma LAKARNCHUA \\ ORCID: 0000-0001-5461-8066 \\ Language Institute \\ Chulalongkorn University \\ Bangkok, THAILAND
}

Sean BALME

ORCID: 0000-0003-3032-5095

Language Institute

Chulalongkorn University

Bangkok, THAILAND

Andrew MATTHEWS

ORCID: 0000-0002-9725-7413

Language Institute

Chulalongkorn University

Bangkok, THAILAND

Received: 21/06/2019 Accepted: 13/04/2020

\begin{abstract}
As an option to help cope with challenges such as differing student needs, lack of student interest, and limited contact hours, the commercial learning management system (LMS) Blackboard was used to support a flipped classroom approach in a first-year English as a foreign language course at a large Thai public university. The aims of the study were to determine students' perceptions of the course and how it affected their second language writing anxiety, in order to improve later versions of the course. Data were collected over the course of two non-consecutive measures from 272 participants in the first semester and 141 in the second. Data on students' perceptions and anxiety were collected using a questionnaire and the Second Language Writing Anxiety Inventory (Cheng, 2004). After quantitative and qualitative analysis, results showed that participants' second language writing anxiety was not significantly affected by the modified course. Their perceptions of the course appeared to be impacted by technological difficulties that occurred. The results seem to indicate that frustration with technology should be of greater concern when attempting to utilize an LMS or similar platform.
\end{abstract}

Keywords: Learning management system, education, technology, EFL

\section{INTRODUCTION}

In Thailand, English serves as a tool to "[link] Thailand culturally, intellectually and commercially with other ASEAN countries and the rest of the world" (Baker, 2012, p. 18). Yet, despite this important status, the teaching and learning of English among Thai students is problematic. The challenges facing numerous Thai learners of English as a foreign language (EFL) are exemplified by the difficulties seen in the general introductory English courses offered to first-year students of Chulalongkorn University, Thailand's oldest institution of higher education.

Currently, all of the first-year students of Chulalongkorn University (except those in the Faculty of Arts) are required to take two general introductory English courses, Experiential English I and Experiential English II, offered by the Chulalongkorn University Language Institute. These courses have been designed to provide 
students with the language skills necessary to function in more advanced English courses at the university. Although the Experiential English courses provide many transferable skills, such as critical thinking skills, collaboration skills, and research skills, and place an emphasis on students' language development, they have several drawbacks. One is that students have only a single three-hour class every week; for many students, this may be the only exposure they have to English throughout the week. Additionally, regardless of their initial ability in English, all students are taught using the same basic material and administered the same examinations. All of these factors may disadvantage students at both ends of the ability spectrum.

Moreover, a major component of the examinations the students are required to sit, as well as the courses themselves, is writing, which may add an extra layer of difficulty because writing is a complex skill, necessitating the interplay of receptive, expressive, and reflective skills, and the achievement of an acceptable level of writing is an arduous task (Deane, 2011). For students of the Experiential English courses, there is an added level of challenge: as they are learners of English as a foreign language (EFL), they are being asked to engage with a writing system that has marked differences from the one they are familiar with, and this can be highly challenging and even anxiety-provoking (Mat Daud, Mat Daud and Abu Kassim, 2005; Weigle, 2002). The literature has shown negative correlations between the anxiety aroused by being asked to write in a second or foreign language (known as second language writing anxiety) and various academic outcomes, including lower standardized writing test scores (Jahin, 2012).

As the major purpose of both Experiential English courses is to prepare students for further, more specific English courses throughout their university career, it would seem highly pertinent to ensure they are indeed establishing a strong linguistic foundation upon which students may pursue future academic endeavors. At present, the limitations outlined previously may hinder the achievement of this goal. In seeking to address the shortcomings of the Experiential English courses-its limited contact time, its use of non-differentiated materials and examinations, the potential for anxiety resulting from an emphasis on writing-it was decided to implement a flipped classroom approach, aided by the commercial learning management system Blackboard. This particular learning management system, or LMS, was selected chiefly due to practicality (as Chulalongkorn University pays the licensing fee for its use throughout the institution), but it also happens to be an oft-used LMS in higher education settings and leading international proprietary LMS (Carvalho, Areal, and Silva, 2011; Zanjani et al., 2017).

Interventions of a similar nature-technology-aided flipped classrooms-have been attempted in other contexts (Elmaadaway, 2018; Cheng et al., 2017), but little has been done in the Thai EFL context. As such, little concrete information exists on the effects of attempting such an endeavor with Thai EFL learners. Thus, in conducting this research, the researchers aimed to determine if such a course would indeed help to alleviate the aforementioned problems, with the understanding that such a broad objective may lend itself only to a research study of an exploratory nature. As the primary role of the researchers is educators, however, it was felt that any insights gained would be valuable at a pedagogical level. This particular study is part of a larger project examining the effects of utilizing an LMS to implement a flipped classroom approach at Chulalongkorn University, looking at issues such as teachers' perceptions and links with student academic achievement and. However, this article will focus on students' perceptions of the use of a course employing a flipped classroom approach via a commercial learning management system, and how the course impacted their levels of second language writing anxiety, so as to inform later iterations of the course.

\section{LITERATURE REVIEW}

\section{The Flipped Classroom Approach}

The flipped classroom approach refers to an alternative model of instruction where the timing of what are traditionally seen as classroom activities are swapped with what are usually seen as activities that occur outside the boundaries of a classroom (Cheng et al., 2017). According to Elmaadaway (2017), a flipped classroom is "an appropriate alternative to conventional, unidirectional forms of knowledge acquisition" (p. 480). Novel content is delivered to students via reading texts or short videos outside of the classroom. Time in the classroom is then spent further developing this knowledge through a variety of methods, such as interacting with the teacher and peers or taking part in discussions or debates (Brame, 2013). Essentially, a flipped classroom approach allows class time to be used to expand ideas and complete more sophisticated 
language- and thinking-intensive tasks, as it pushes much of the core input for students into their own time. This allows for flexible and convenient learning (Squillante, Wise, and Hartey, 2014).

There are a number of theoretical underpinnings for flipped classrooms. One of the key ones is constructivism, which refers to learning theories, based on the work of scholars like Vygotsky and Piaget, that support the need for shaping comprehension and knowledge of the world by participating in experiences and engaging in reflection on them to create mental models of information (Bishop \& Verleger, 2013; Cheng, Ritzhaupt, \& Antonenko, 2018; Eppard \& Rochdi, 2017). In a flipped classroom, each learner is expected to dynamically engage with the material, the teacher, and his/her peers, rather than being fed information, with the end result being an individual construction of knowledge (Cheng, Ritzhaupt, \& Antonenko, 2018; Eppard \& Rochdi, 2017). Thus, vital components of the flipped classroom are active learning and student-centeredness (Ahmad, 2016).

Theoretical support for flipping classrooms can also be found in the concept of Mastery Learning, based on the work of Bloom. A key tenet of mastery learning is offering students multiple opportunities to achieve learning objectives and demonstrate their knowledge. The pacing of the learning process is left up to individual learners and correction is given where needed (Eppard \& Rochdi, 2017; Lane-Kelso, 2015). In a flipped classroom approach, course material is made available to students prior to class time, so they may view and engage with it on their own time and at their own speed. In the classroom, they must utilize that knowledge to participate in exercises that support deep learning and critical thinking in regards to the content (Moraros et al., 2015).

Research of student perceptions of flipped classrooms has found generally positive views of its use (Bishop and Verleger, 2013). One study by Butt (2014) on the use of a flipped classroom approach in a final-year actuarial course at an Australian university found a large number of students deemed it beneficial to their academic pursuits and supported its use in the future. A majority of the graduate-level epidemiology students researched by Moraros et al. (2015) deemed the effectiveness of a flipped classroom to be quite high, with wholly $100 \%$ of the international students who participated in the research rating the approach as either very effective or somewhat effective. In addition to positive perceptions of its use, flipped classrooms have also been found to positively impact learning outcomes, such as the significantly improved writing proficiency of the Japanese participants in Leis, Cooke, and Tohei's (2015) research.

A key aspect of a flipped classroom is the delivery of new course material beyond the confines of class time. According to Bishop and Verleger (2013), however, it should not be understood that the mere assignment of reading texts outside of class, followed by participation in classroom-based discussions, constitutes a flipped classroom. Instead, they define a flipped classroom as "an educational technique that consists of two parts: interactive group learning activities inside the classroom, and direct computer-based individual instruction outside the classroom" (Bishop and Verleger, 2013, para. 13). Learning management systems have been one option for providing the latter.

\section{Learning Management Systems}

In simple terms, a learning management system or an LMS is "an online portal that connects lecturers and students" (Squillante, Wise, and Hartey, 2014, p. 5). Using an LMS like Blackboard to deliver course material allows it to not only be easily accessible online at any time and any place, but also enables both instructors and students to engage in continual monitoring, feedback exchange, and assessment (Bradford, Porciello, Balkon, and Backus, 2007).

Different LMSs have different features that facilitate the teaching and learning process. Blackboard, for example, allows the online sharing of course materials, online assignment submission, and asynchronous discussion (Heirdsfield et al., 2011). The free open source LMS Moodle offers many of these same features, as well as online quiz capabilities (Carvalho, Areal, and Silva, 2011)

The literature reveals varied uses of LMSs. For instance, Moodle was integrated into a class meant to familiarize ninth grade students with online learning (List and Bryant, 2009). In a Thai EFL context, Sanprasert (2010) investigated how an LMS can be used to foster learner autonomy in a blended learning environment. Results showed that different aspects of autonomy were supported by the utilization of an LMS. The use of a learning 
management system to implement a flipped classroom can be seen in the study conducted by Moraros et al. (2015), where the learning management system Blackboard was used as a repository for pre-recorded instructor videos that were to be viewed prior to class. Making videos, animations, references of organ system histology, and an online bank of histology items available via Blackboard to students of traditional Chinese medicine was also part of a flipped classroom detailed by Cheng et al. (2017).

\section{Second Language Writing Anxiety}

Cheng (2004) theorizes that second language writing anxiety is multidimensional, comprising physical manifestations of anxiety (such as perspiring), mental distress (such as concerns regarding writing tasks), and avoidance behaviors (such as procrastinating when asked to complete a writing task). Having feelings of distress when asked to engage in writing in a second or foreign language seems to be associated with various negative writing-related outcomes, including poor writing performance, low writing quality, and avoidance of courses and careers where advanced writing is required (Kara, 2013). In general, the research has found that writing anxiety has a debilitating impact on student writing performance (Rezaei and Jafari, 2014). Why this is is still a question of debate among researchers, although several studies point out the fact that writing is most often a solitary endeavor, undertaken in relative isolation (Atay and Kurt, 2006). The highly individualized nature of writing may leave weaker writers floundering without any means of seeking guidance or assistance (Jahin, 2012). For EFL writers, additional difficulties may arise from a perceived lack of enough English for clear expression, as seen with the Turkish subjects investigated by Kara (2013).

However, the use of technology seems to have a positive effect on writing anxiety, with Chuo (2007), for instance, noting a significant decrease in the anxiety levels of learners of a writing course that incorporated WebQuests, a type of inquiry-driven learning that integrates online resources. Kassem (2017) discovered the use of a wiki significantly reduced the writing anxiety levels of Saudi Arabian students enrolled in a business writing course. Even when no apparent effect is seen on writing anxiety, the incorporation of technology does still seem to positively affect the overall writing experience. While Pae's (2007) research of 15 university level Korean students who participated in a wiki-aided English writing course found that the majority of participants' anxiety levels dropped, the difference between pre- and post-course anxiety levels was not significant. What the participants revealed, however, was that they found the use of a wiki to be a fun, beneficial way to practice writing.

\section{METHODOLOGY}

\section{Method}

This study was a mixed methods study, and involved both quantitative and qualitative data. The decision to use mixed methods was because it "makes room for both the exploratory inductive process that begins with empirical evidence of the particular and proceeds to a level of abstracting/theorizing/generalizing and the confirmatory deductive process of hypothesis testing of theories" (Rocco et al., 2003, p. 22). As a study of this nature had yet to be conducted in this particular context, the researchers wanted to evaluate the outcomes from a number of angles and a mixed methods approach seemed to fulfill this aim.

There were three broad phases to the study. The key activities for each phase, such as the design of a course using the flipped classroom approach and quantitative and qualitative analysis of the data, are summarized in the following table.

Table 1. Outline of the research phases and key activities undertaken during each phase

\begin{tabular}{cl}
\hline Phase & \multicolumn{1}{c}{ Key Activities } \\
\hline 1 & - Flipped classroom course design \\
\hline 2 & Preparation for implementation \\
\hline 3 & - Flipped classroom course implementation \\
\hline
\end{tabular}




\section{DESIGN AND PREPARATION}

In the first phase of research, which preceded data collection, two of the researchers designed lessons that utilized the flipped classroom approach based on the core syllabus of Experiential English II. In designing the course, the researchers considered Bishop and Verleger's (2013) warning against restricting flipped classroom activities to asynchronous video lectures, close-ended problems, and quizzes testing discrete items. Such activities, while useful and necessary to an extent, run counter to elements that constructivism and mastery learning set forth as important to learning, elements such as meaningful interaction (Cheng, Ritzhaupt, \& Antonenko, 2018; Eppard \& Rochdi, 2017). Therefore, the researchers attempted to create a balance between different types of activities, including, for example, online quizzes, open-ended questions related to external YouTube videos, and an assignment for students to create a page on the social network site Facebook related to class content.

Aside from the theoretical concepts associated with constructivism and mastery learning, a guiding, more practical, principle adopted in lesson planning was to not to make the content of course seem wholly different from what students would have been exposed to in the traditional setting, as that was felt to be unfair and might have proved anxiety-provoking for the research participants who would undoubtedly compare their own experiences to those of their peers taking the same course. That is, while the delivery of the content and the way students were asked to work with it was different from that of other students taking the Experiential English II course, the actual content was kept as similar as possible.

Once the new lessons had been planned, assignment materials and corresponding instructions were uploaded to the LMS used in the study, which was Blackboard. An example of an assignment can be seen in Figure 1.

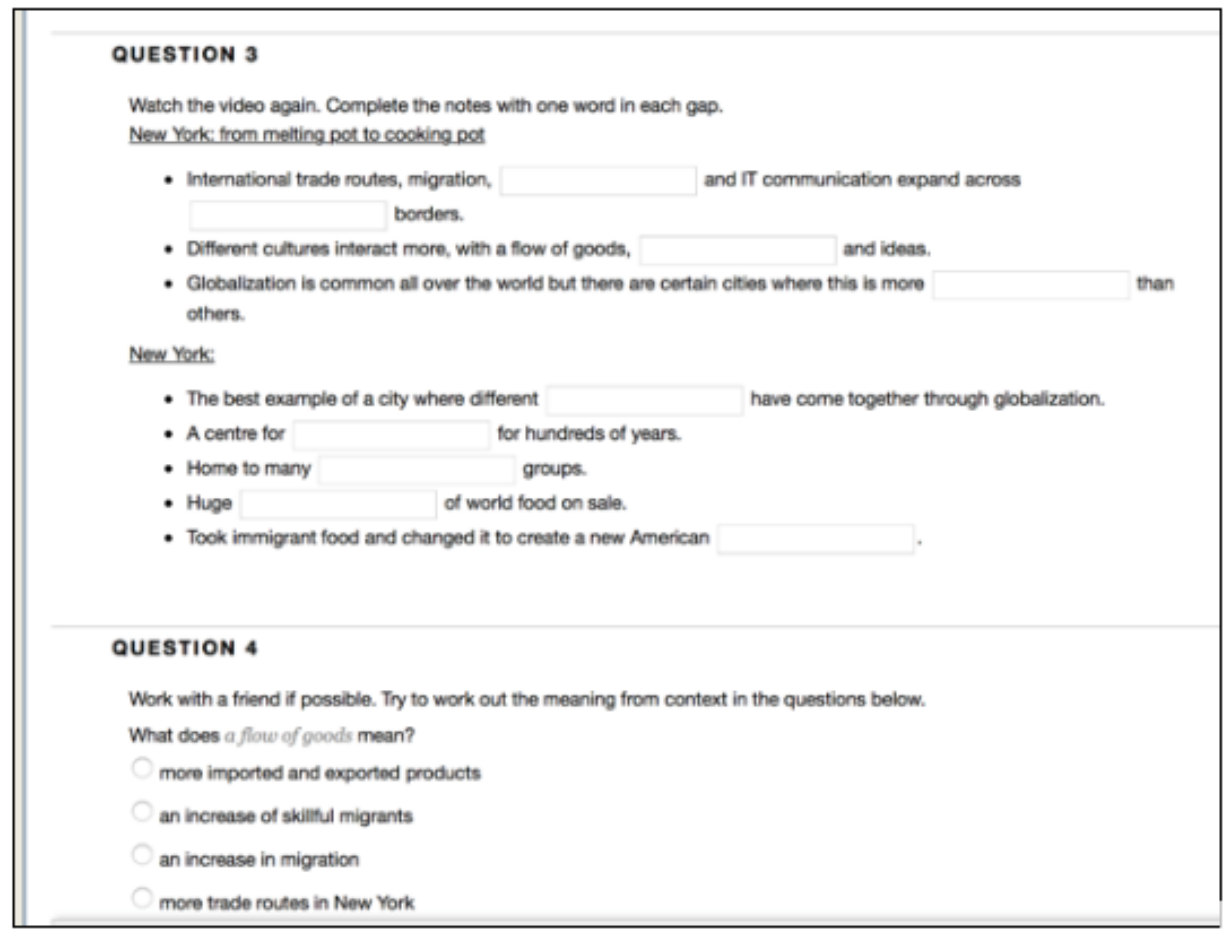

Figure 1. An example of an LMS-based assignment

Initially, the researchers had also hoped to incorporate gamification principles as a means to motivate students to access English more frequently than they had under the present structure of the course. The format of the version of the Blackboard learning management system that was being utilized, particularly its cosmetic aspects, did not lend itself readily to gamification on a wide scale, at least not to the extent it was visualized by the researchers. Consultation with the instructors who joined the project before the launch of the course, furthermore, also yielded great reluctance to utilize gamification. As such, it was decided the game-based learning platform Kahoot! would be incorporated into the structure of the course, but it would only be used in the classroom and only on a volunteer basis. 
Once the course materials were uploaded to Blackboard, the researchers publicized the study to instructors of the course. Interested instructors took part in a short single-day training session offered by one of the researchers in order to familiarize themselves with the lessons and the Blackboard learning management system. This occurred before the start of the course.

\section{Participants}

Due to time and personnel constraints, it was decided to carry out the research only with students of Experiential English II (although it should be noted that Experiential English I and II share the same difficulties outlined previously). Thus, the population of the study was all first-year students of Chulalongkorn University taking the Experiential English II course offered by the Chulalongkorn University Language Institute. This was approximately 5,000 students.

As the study was meant to be exploratory in nature, it was decided that the research sample was to be a convenient sample. The research participants were students of the instructors of the course who had interest in taking part in the research, i.e. the instructors were the ones who chose to use the modified course. The participants were students studying in the Experiential English II course during two non-consecutive semesters. The following table summarizes information on the participants of this study.

Table 2. Information on participants of the study

\begin{tabular}{cccc}
\hline Semester & Total number of participants & Number of classes & Gender \\
\hline 1 & 272 & 9 & Male: $45.9 \%(125)$ \\
2 & 141 & 5 & Female: $54.0 \%(147)$ \\
& & & Male: 66 \\
\end{tabular}

As seen in the table, the first semester had a total of 272 participants, who were in nine different classes or sections. Two of these sections were taught by researchers in this study, and the remaining seven were taught by three instructors who chose to be part of the research (one teacher was in charge of four sections, one taught two, and the final taught one). In the second semester, data were collected from five sections of 141 students in total, with two taught by the researchers and the remaining three under the supervision of three instructors who chose to take part in the research. The number of female participants slightly outnumbered males in both semesters.

\section{Data Collection}

Data collection took place once the course was implemented. The course ran for a total of 16 weeks, with one week off for the midterm and one week off for the final examinations. Two data collection instruments were utilized to gather information on students' writing anxiety and perceptions of the course.

At the start of the course, all instructors of the Experiential English II course asked their students to complete the Second Language Writing Anxiety Inventory or the SLWAI (Cheng, 2004), available both in its original English and also translated into Thai, for students who were more comfortable with this language, in order to determine a baseline anxiety level for both research participants and their peers. One's score on this 22item inventory represents one's level of anxiety when asked to write in a second or foreign language. The inventory conceptualizes second or foreign language writing anxiety as a multidimensional construct, the confluence of avoiding situations where one must write, physical symptoms such as numbness, and mental anguish associated with writing in a second or foreign language. A high score means the respondent has a high level of anxiety when engaging in this activity (Atay \& Kurt, 2006; Cheng, 2004).

The SLWAI was made available as an online questionnaire. It must be noted that all students were informed that choosing to complete the SLWAI was completely voluntary and they would not be penalized or rewarded for doing so. They were informed that their responses were purely for research purposes and that by participating, they were helping to improve the course. 
Each semester utilized a different procedure to ensure the SLWAI respondents' anonymity. In the first semester, respondents were asked to enter their section number, the first letter of their name, and the last four digits of their cell phone number. The idea was that the information would be given a unique marker, but be untraceable to any one individual. While confidentially was indeed maintained, it was discovered that statistical analyses suffered as a result of some respondents entering differing information before and after the course-for example, a respondent entered three digits on the inventory before the course started and four on the one towards the end of the course. Although the three digits were identical to the first three of the four-digit sequence seen in the latter inventory, and the initial letter and section numbers that were input matched, it was impossible to say with certainty if the information was from the same respondent. Due to this uncertainty, vigorous statistical analysis could not be run on the first set of data collected.

In the proceeding data collection period, quasi-anonymity was maintained by having students identify themselves only by their section number and their student identification number. While the latter is a unique sequence of 10 digits assigned to each student, access to personal information associated with the number is highly restricted. Attempting to attach a name to a student identification number, for example, would require going through a number of official channels. The researchers chose to ask for this number, however, in order to facilitate data analysis with minimal damage to the students' privacy.

At the conclusion of the course, the participants and other students taking the course were again asked to complete the SLWAI, as well as answer several open-ended questions regarding the course. The researchers asked the instructors to assure the students again that their responses were for research and course improvement purposes. This short questionnaire was also available online in both Thai and English. The data from the questionnaires were used to supplement the SLWAI data and to reveal information regarding students' perceptions of the course.

The SLWAI scores as well as both the students' responses to the questionnaire were collected for data analysis, with the research participants' data being grouped by referring to their section or class number.

\section{Data Analysis}

The data collected over the course of two non-consecutive semesters were subjected to similar forms of analysis. However, due to the issues discussed previously, only descriptive statistical analyses were run with the SLWAI data from the first semester's participants. The data from the SLWAI administered during the second semester were analyzed with an independent samples t-test. The SLWAI data of the research participants in both semesters were also compared to data taken from a random sample of students from the population. The responses to the questionnaires from both semesters underwent conventional content analysis, a form of quantitative data analysis. In this form of content analysis, the data are examined in order to yield categories for further analysis, rather than presupposing categories into which data can be sorted. This form of content analysis is useful for revealing information about a phenomenon (Hsieh \& Shannon, 2005).

\section{RESULTS}

The results from the data analysis are presented and discussed by semester. It should also be noted that data from the first semester were treated as pilot study data, i.e. serving to elucidate any problems with the data collection procedures or the modified course.

\section{Findings from the First Semester of Data Collection}

Following the first semester utilizing the modified Experiential English II course, the researchers examined students' comments on the questionnaires. Based on the data from these, several small changes were made to the content on the Blackboard system in response to research participants' comments. For instance, some announcements and instructions were reworded for clarity, as there were remarks that seemed to indicate students were not able to easily find some of the materials or follow some of the assignments. Links to other websites were checked for accuracy and some content items were rearranged for greater convenience. 
As thorough statistical analysis on the SLWAI scores could not be done, it was decided to note the average total score for each group and determine which anxiety level the students, as a whole, fell into. According to Atay and Kurt's (2006) criteria, SLWAI scores may be used to categorize respondents as being at a high anxiety level (an SLWAI score greater than 83), an average anxiety level (an SLWAI score between 58 and 83), or a low anxiety level (an SLWAI score equal to or less than 58). The following table shows findings regarding the anxiety levels of the students, with "BB" referring to the group that was taught using the modified course and "Non-BB" referring to their traditionally taught counterparts.

Table 3. Categorization of mean SLWAI scores of the BB and non-BB group

\begin{tabular}{cllc}
\hline Group & \multicolumn{1}{c}{ Mean Score } & Categorization \\
\hline \multirow{2}{*}{ BB } & Pre-course SLWAI & 64.1 & average \\
& Post-course SLWAI & 62.8 & average \\
& Pre-course SLWAI & 59.6 & average \\
\multirow{2}{*}{ Non-BB } & Post-course SLWAI & 63.4 & average \\
\hline
\end{tabular}

As can be seen, both groups started off with mean SLWAI scores that placed them at the average level of anxiety. This did not change at the conclusion of the course. However, it should be noted that a slight drop in the mean SLWAI score occurred in the BB group, while a slight increase was seen in the non-BB group. Though these changes cannot be analyzed statistically, they are still interesting to note. Overall, however, the first semester of data collection did not yield any quantitative results of particular note.

In terms of the qualitative data from the questionnaires, only $20 \%(\mathrm{n}=39)$ of respondents elected to answer the open-ended questions, and thus, it was understood that any insights gleaned would likely not be overly representative of the participants. The key insight found upon conducting content analysis on the students responses was suggested avenues for minor changes to the content and delivery of content via Blackboard. The following table shows some sample comments from the respondents (translated from Thai).

Table 4. Sample comments from the first semester respondents

\begin{tabular}{ll}
\hline Respondents & \multicolumn{1}{c}{ Comment } \\
\hline Respondent 8 & There should be more interesting media and YouTube videos on the site itself. \\
Respondent 19 & We should be able to download PDFs. \\
Respondent 22 & Some of the materials are not interesting and are hard to find. \\
\hline
\end{tabular}

It might be noted, however, that within the small amount of responses that were logged, $30.8 \%$ of the respondents claimed to enjoy learning using a textbook alone, as opposed to using the textbook augmented by an LMS. One respondent even noted (in English): "Book is always better".

\section{Findings from the Second Semester of Data Collection}

It was found that the implementation of a flipped classroom approach via Blackboard did not seem to lead to any quantifiable differences in the second language writing anxiety of the research participants and their peers taking the course without the support of the Blackboard LMS. Statistical analysis using independent samples t-tests determined that the SLWAI scores of BB and non-BB groups were comparable at the start of the course. At the end of the data collection period, the mean writing anxiety level of both groups did show a reduction but when an independent samples t-test was run on the set of scores obtained at the conclusion of the course, no statistically significant difference was found, $\mathrm{t}(100)=1.2, p=0.25$. It would appear then that taking the flipped classroom course delivered via Blackboard did not affect the writing anxiety levels 
of the research participants in a discernible way. In the post-course questionnaire, however, some of the respondents made remarks that appeared to refer to their anxiety and how the course affected it. Some of these remarks appeared to point to an positive effect, while some seemed to indicate the course did not have a positive impact on anxiety. A sample of these comments can be seen in the table below.

Table 5. Comments related to anxiety from second semester respondents

\begin{tabular}{|c|c|}
\hline Respondents & Comments \\
\hline Respondent 243 & When we take this course, it helps us to destroy the wall of fear of using English. \\
\hline Respondent 402 & This course reduces your fear about English. \\
\hline Respondent 619 & $\begin{array}{l}\text { This course made me enjoy and have fun with learning, even though in the first few weeks, I } \\
\text { was scared and did not like English. }\end{array}$ \\
\hline Respondent 317 & Students who do not have writing skills will feel pressure and not want to take this course. \\
\hline Respondent 591 & $\begin{array}{l}\text { I want this course to focus on speaking more in order to increase confidence in speaking } \\
\text { because some friends still do not feel brave enough to speak English because they are scared } \\
\text { of making mistakes. }\end{array}$ \\
\hline
\end{tabular}

The first three remarks suggest taking the course may have alleviated these respondents' negative feelings towards the English language and the learning of it. The two last comments, however, appear to point to the course provoking feelings of anxiety. Interestingly, even though one of the aims of the modified course was to reduce writing anxiety by introducing the flipped classroom approach and bringing in the LMS so students could pace their own learning and have constant access to assistance, the second to last comment appears to imply that this goal was not reached. Some students were still concerned when they were asked to engage in writing. The small number of comments that mentioned anxiety or related emotions, however, does not allow a conclusive supposition regarding the impact of the modified course on the participants' writing anxiety.

It must be noted that several difficulties were encountered while undertaking data collection in the second semester, and these no doubt affected the responses that were gathered from the research participants. The first and most impactful issue was the problematic nature of the learning management system used in the investigation. Around the time of data collection, there was an administrative decision for the entire Blackboard learning management system to be upgraded from version 2014 to 2017 . There were several problems associated with this upgrade, including some missing information and access issues on the part of both instructors and students. These and other technical issues were the subject of some irritation among the participants of the study. A number pointed out various problems they encountered while using the learning management system. The following are some sample comments regarding difficulties involved with the use of the Blackboard LMS. These are taken from the short post-course open-ended questionnaire and translated to English from Thai. The most baldly explicit condemnation is seen in the last comment.

Table 6. Sample comments regarding difficulties from second semester respondents

\begin{tabular}{cl}
\hline Respondents & \multicolumn{1}{c}{ Comment } \\
\hline Respondent 267 & The Blackboard program which is not stable makes it complicated to use. \\
Respondent 402 & Homework cannot be done on an iPad on Blackboard. \\
Respondent 407 & Blackboard should work better; for example, it should allow scrolling up and down on an iPad \\
Respondent 417 & The teacher's various announcements on Blackboard are hard to keep up with. \\
Respondent 568 & Don't use Blackboard. The system is bad. \\
\hline
\end{tabular}


As can be seen from all of the sample remarks, the technical difficulties attached to the LMS made its use unappealing and frustrating for a number of participants. It was noted that the use of an LMS like Blackboard in tandem with a physical textbook was a preferred mode of study for only $41.6 \%$ of the postcourse questionnaire respondents, or 300 students from the total 721 that responded to the questionnaire. More in-depth analysis revealed notable results. For example, of the 22 questionnaire respondents from one section that had utilized Blackboard, more than a third (36.4\%) revealed they would prefer to learn using only the textbook. One respondent went so far as to offer the following criticism of the system, presented here unedited in its original English:

Respondent 496: Should not include blackboard which is very confusing and technologically complicated to use while studying in the class. I personally think that should have invested time in person to practice intensively about various english skills that needed in national examination field.

It seems clear this particular respondent did not perceive the positive aspects of the LMS (e.g. ability to work at one's own pace outside of a physical classroom setting) to outweigh the technological drawbacks.

\section{DISCUSSION}

The overarching aim of this research was to determine how students perceived the use of a course employing a flipped classroom approach via a commercial learning management system, and how their second language writing anxiety were affected by it. As noted at the beginning of the article, this research is highly exploratory in nature, with a great emphasis on examining the views the students had of the modified course so as to improve later iterations of it. Various studies on the use of the flipped classroom approach have found that it benefits students in manifold ways, such as positively affecting their learning achievement, self-regulation, and self-efficacy (Lai \& Hwang, 2016). In this study, the researchers were interested in seeing if the change in how the content of the course was delivered and worked with positively affected students' second language writing anxiety, a concern for this group due to the great importance placed on writing by the course. Overall, no statistically significant differences between the research sample and their counterparts were found in terms of their anxiety levels. As such, the course utilizing a flipped classroom approach aided by an LMS did not seem to impact students' writing anxiety in a discernible manner. It should be noted, though, that while no statistically significant difference was seen between participants learning with the LMS-aided flipped classroom and their counterparts, the mean writing anxiety levels of both groups did drop. This could be taken to mean that the modified course did not lead to a greater degree of anxiety than the regular course. Since anxiety has been linked to negative academic outcomes (Jahin, 2012), the fact that changing the delivery of the course led to a similar outcome in regards to writing anxiety as the traditional course may be seen as slightly promising, as one could implement the modified course with minimal concern for it increasing students' anxiety. Further research may attempt to determine what factors could lead to a significant reduction in writing anxiety when implementing a flipped classroom approach via an LMS. For example, does the ability to engage more with material in class play any part in anxiety reduction, as this has been noted by other researchers as a benefit of the flipped classroom approach (Butt, 2014)?

One of the major limitations of this study was its relatively small sample size, particularly during the second semester of data collection. As noted, participation in the research was on a purely voluntary basis. The research's goals and set-up were publicized to all instructors of the course before the beginning of classes, and although there appeared to be a strong amount of initial interest, ultimately, only a few instructors joined the study, and consequently, only a relatively small number of students were exposed to the modified iteration of the Experiential English II course. Another difficulty in addition to the issue of the relatively small number of participants was the fact that some of the participating instructors seemed to have abandoned the use of Blackboard once the course was underway. That is, some of the earlier assignments and materials were utilized while the later ones were not. What impact this abandonment had on the research results could not be clearly determined and future studies may touch upon how to minimize participant dropout. In future research, it may also be pertinent to determine from the start which participants are, using the terminology of McNally et al. (2017), "flip endorsers" or people with favorable attitudes towards the flipped classroom approach and which are "flip resisters", those who are less likely to favor the flipped classroom approach. The latter group can then be addressed using appropriate measures. 
An interesting matter that arose from this research was how technical issues seem to affect perceptions of a course that is delivered via a technological channel; in this case, the commercial learning management system Blackboard. In examining the participants' comments, it was made abundantly clear that technical issues seem to play a strong role in how a technology-aided course is perceived. It might not even be an exaggeration to say that the benefits of the course, as noted in the comments from the research participants, appeared to have been overshadowed in part by the persistent technical issues. Indeed, this is a phenomenon that has been discussed in the literature. Elmaadaway (2017) cautioned that complications could arise in a flipped classroom approach where students are required to watch videos and complete work in an online environment, as these activities might be adversely affected by factors such as Internet connectivity or device functionality. Nah, White, and Sussex (2008) concluded that negative comments regarding a cell phoneaccessible site for the practice of listening skills resulted from participants experiencing technical problems while attempting to complete assignments. Hara and Kling (1999) noted in their study of an online graduate course that their participants expressed irritation with some technological aspects of taking a web-based course, such as the inability to download or access materials. The researchers concluded "the substantial frustrations reported by our informants...were not incidental and could actually impede their learning" (para. 1). Contrarily, a technological channel that is perceived in a favorable light could lead to favorable outcomes, such as the personal communication application LINE, used in Chen Hsieh, Wu, and Marek's (2016) research, leading EFL learners to feel their speaking proficiency was improved, their interactions were more effective, and their writing was enhanced.

As can be seen from the comments taken from the questionnaires, the students investigated in this study felt frustration with the technology they were asked to use, pinpointing such problems as the unstable nature of the Blackboard system and certain features being unavailable. While the inability to access the LMS due to the upgrade was unforeseen and unfortunate, other issues may have resulted from the choice of LMS. Analysis of users' views of Blackboard by Zanjani et al. (2017) revealed one of its major drawbacks is its lack of a user-friendly interface. Although assignment instructions were made available in what were deemed highly visible parts of the interface, some students may have required additional guidance in navigating it. Additional guidance may have also been necessary because it has been noted Thai students may not be used to operating on their own in an active learning context, such as one created by using a flipped classroom approach (Suranakkharin, 2017; Thaichay \& Sitthitikul, 2016). Suranakkharin (2017), in a study of using the flipped classroom approach to help Thai EFL learners master English collocations, discussed the importance of having a facilitator in the success of flipped classroom instruction and subsequent student perceptions. Future research might focus on the provision of better technological and overall support, and how it impacts participants' perceptions.

\section{CONCLUSION}

Overall, it would seem that when choosing to incorporate technology into the teaching and learning process, great care must be taken to offer consistent technical support and prepare alternative plans in scenarios where the technological option is simply not viable. This is one of the major insights gained from this research and further research should explore how to minimize these technical issues so as to help students fully benefit from a course that utilizes a technological component. Whether the technical issues they experienced affected the students' writing anxiety level or other factors was not investigated in this research, but may also be a fascinating avenue of study to pursue.

Acknowledgements: This research was funded by the Learning Innovation Center of Chulalongkorn University, Bangkok, Thailand. Thank you to the anonymous reviewers' comments that helped improve this article. 


\section{BIODATA and CONTACT ADDRESSES of AUTHORS}

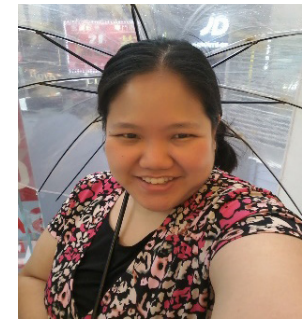

Onuma LAKARNCHUA is a graduate of the English as an International Language program at Chulalongkorn University in Bangkok, Thailand. She is a full-time lecturer for the Chulalongkorn University Language Institute. She teaches English as a foreign language courses at both the undergraduate and graduate level. She also does translation and editing work. Her research interests include the integration of technology in English as a foreign language education, affect in language learning, and incidental learning.

\section{Onuma LAKARNCHUA}

Chulalongkorn University Language Institute

Address: Prem Purachatra Building, Phayathai Road, Pathumwan, Bangkok 10330

Phone: +662 2186012

E-mail: onuma.1@chula.ac.th

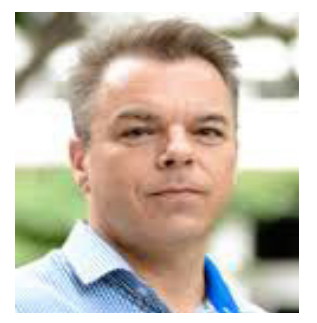

Sean BALME is Canadian and has worked as a teacher in Canada, South Korea and Thailand since 1995. In 2003, he received a Master in Education from the University of Manchester and has been teaching at Chulalongkorn University for the past 15 years. While at Chulalongkorn, the focus of many of his classes have been with Business Communication in the form of negotiation, presentations, Business letter writing and Business Research Report Writing. He works on creating online courses in his spare time.

\section{Sean BALME}

Chulalongkorn University Language Institute

Address: Prem Purachatra Building, Phayathai Road, Pathumwan, Bangkok 10330

Phone: + 66830481968

E-mail: Sean.b@chula.ac.th

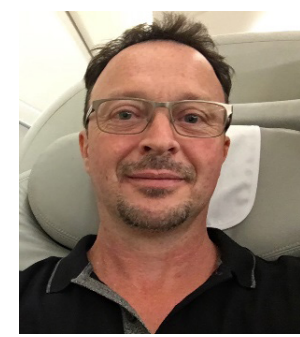

Andrew MATTHEWS started his career in technology before becoming fascinated with education. He retrained as an English teacher which has allowed him to travel and work in some fascinating places. His knowledge of technology inevitably led him to blended learning and he is currently writing online courses to enable students to make use of technology whilst maintaining a strong pedagogical foundation. His teaching philosophy is guided by constructivism and strong learning outcomes. Future research will be based around these core principles.

\section{Andrew MATTHEWS}

Chulalongkorn University Language Institute

Address: Prem Purachatra Building, Phayathai Road, Pathumwan, Bangkok 10330

Phone: +662 2186012

E-mail: altandymail@gmail.com 


\section{REFERENCES}

Ahmad,S.Z. (2016). The flipped classroom model to develop Egyptian EFL students' listening comprehension. English Language Teaching, 9(9), 166-178.

Atay, D., \& Kurt, G. (2006). Prospective teachers and L2 writing anxiety. Asian EFL Journal, 8(4), 100-118.

Baker, W. 2012. English as a lingua franca in Thailand: Characterizations and implications, Englishes in Practice, 1, 18-27.

Bishop, J. L. \& Verleger, M. A. (2013). The flipped classroom: A survey of the research. In American Society for Engineering Education, 120th ASEE Annual Conference \& Exposition.

Retrieved June 11, 2018 from https://www.asee.org/public/conferences/20/papers/6219/view

Bradford, P., Porciello, M., Balkon, N., \& Backus, D. (2007). The Blackboard learning system: The be all and end all in educational instruction? Journal of Educational Technology Systems, 35(3), 301-314.

Brame, C., (2013). Flipping the classroom. Vanderbilt University Center for Teaching. Retrieved Jan. 10, 2017 from http://cft.vanderbilt.edu/guides-sub-pages/flipping-the-classroom

Butt, A. (2014). Student views on the use of a flipped classroom approach: Evidence from Australia. Business Education \& Accreditation, 6(1), 33-43.

Carvalho, A., Areal, N., \& Silva, J. (2011). Students' perceptions of Blackboard and Moodle in a Portuguese university. British Journal of Educational Technology, 42(5), 824-841.

Chen Hsieh, J. S., Wu, W. C. V. \& Marek, M. W. (2016). Using the flipped classroom to enhance EFL learning. Computer Assisted Language Learning. 30(1-2), 1-21.

Cheng, L., Ritzhaupt, A.D., \& Antonenko, P. (2018.) Effects of the flipped classroom instructional strategy on students' learning outcomes: A meta-analysis. Education Technology Research and Development, $67(4), 1-32$.

Cheng, X., Lee, K.K.H, Chang, E. Y., \& Yang, X. (2017). The "flipped classroom" approach: Stimulating positive learning attitudes and improving mastery of histology among medical students. Anatomical sciences education, 10(4), 317-327.

Cheng, Y. S. (2004). A measure of second language writing anxiety: Scale development and preliminary validation. Journal of Second Language Writing, 13(4), 313-335.

Chuo, T.I. (2007). The effects of the WebQuest writing instruction program on EFL learners' writing performance, writing apprehension, and perception. TESL-EJ, 11(3), 1-27.

Deane, P. (2011). Writing assessment and cognition (ETS Research Report RR-11-14). Princeton, NJ: Educational Testing Service.

Elmaadaway, M. A. N. (2018). The effects of a flipped classroom approach on class engagement and skill performance in a blackboard course. British Journal of Educational Technology, 49(3), 479-491.

Eppard, J., \& Rochdi, A. (2017). A framework for flipped learning. 13th International Conference Mobile Learning (pp. 33-40). UAE: Zayed University.

Hara, N., \& Kling, R. (1999). Students' frustrations with a web-based distance education course. First Monday, 4(12), Retrieved Apr. 12, 2017 from https://journals.uic.edu/ojs/index.php/fm/article/ view/710/620

Heirdsfield, A., Walker, S., Tambyah, M., \& Beutel, D. (2011). Blackboard as an online learning environment: What do teacher education students and staff think? Australian Journal of Teacher Education (Online), 36(7), 1-16.

Hsieh, H. F., \& Shannon, S. E. (2005). Three approaches to qualitative content analysis. Qualitative health research, 15(9), 1277-1288.

Jahin, J.H. (2012). The effect of peer reviewing on writing apprehension and essay writing ability of prospective EFL instructors. Australian Journal of Teacher Education, 37(11), 60-84. 
Kara, S. (2013). Writing anxiety: A case study on students' reasons for anxiety in writing classes. Anadolu Journal of Educational Sciences, 3(1), 103-11.

Kassem, M. A. M. (2017). Developing business writing skills and reducing writing anxiety of EFL learners through wikis. English Language Teaching, 10(3), 151-163.

Lai, C. L., \& Hwang, G. J. (2016). A self-regulated flipped classroom approach to improving students' learning performance in a mathematics course. Computers \& Education, 100, 126-140.

Leis, A., Cooke, S., \& Tohei, A. (2015). The effects of flipped classrooms on English composition writing in an EFL environment. International Journal of Computer-Assisted Language Learning and Teaching (IJCALLT), 5(4), 37-51.

List, J. \& Bryant, B. (2009). Integrating interactive online content at an early college high school: An exploration of Moodle, Twitter and Ning. Meridian, Raleigh, NC. Retrieved June 11, 2018 from https:// meridian.ced.ncsu.edu/archive/winter2009/List/index.htm

Liu, Y. (2008). The effects of error feedback in second language writing. Arizona Working Papers in SLA \& Teaching, 15(1), 65-79.

Mat Daud, N.S., Mat Daud, N., \& Abu Kassim, N.L. (2005). Second language writing anxiety: Cause or effect? Malaysian Journal of ELT Research, 1, 1-19.

McNally, B., Chipperfield, J., Dorsett, P., Del Fabbro, L., Frommolt, V., Goetz, S., \& Rung, A. (2017). Flipped classroom experiences: Student preferences and flip strategy in a higher education context. Higher Education, 73(2), 281-298.

Moraros, J., Islam, A., Yu, S., Banow, R., \& Schindelka, B. (2015). Flipping for success: Evaluating the effectiveness of a novel teaching approach in a graduate level setting. BMC Medical Education, 15(1), 27.

Lane-Kelso, M. (2015). The pedagogy of flipped instruction in Oman. Turkish Online Journal of Educational Technology-TOJET, 14(1), 143-150.

Nah, K. C., White, P., \& Sussex, R. (2008). The potential of using a mobile phone to access the Internet for learning EFL listening skills within a Korean context. ReCALL, 20(3), 331-347.

Pae, J. K. (2007). Wiki-based English writing: Its effect on English writing proficiency and anxiety and Korean learners' perceptions. Multimedia-Assisted Language Learning, 10(1), 81-105.

Rezaei, M., \& Jafari, M. (2014). Investigating the levels, types, and causes of writing anxiety among Iranian EFL students: A mixed method design. Procedia-Social and Behavioral Sciences, 98, 1545-1554.

Rocco, T., Bliss, L., Gallagher, S. \& Pérez-Prado, A. (2003). Taking the next step: Mixed methods research in organizational systems. Information Technology, Learning and Performance Journal, 21(1), 19-29.

Sanprasert, N. (2010). The application of a course management system to enhance autonomy in learning English as a foreign language. System, 38(1), 109-123.

Squillante, J., Wise, L., \& Hartey, T. (2014). Analyzing Blackboard: Using a learning management system from the student perspective. Mathematics and Computer Science Capstones. Paper 20.

Suranakkharin, T. (2017). Using the flipped model to foster Thai learners' second language collocation knowledge. 3L: The Southeast Asian Journal of English Language Studies, 23(3), 1-20.

Thaichay, T., \& Sitthitikul, P. (2016). Effects of the flipped classroom instruction on language accuracy and learning environment: A case study of Thai EFL upper-secondary school students. Rangsit Journal of Educational Studies, 3(2), 35-64.

Weigle, S.C. (2002). Assessing writing. Cambridge: Cambridge University Press.

Zanjani, N., Edwards, S. L., Nykvist, S., \& Geva, S. (2017). The important elements of LMS design that affect user engagement with e-learning tools within LMSs in the higher education sector. Australasian Journal of Educational Technology, 33(1). 